\title{
The effect of temperature on association constants and conductivities of ferrous chloride and ferric chloride in DMF-water mixtures
}

\author{
Süheyla Pura Ergin \\ Istanbul University, Engineering Faculty, Department of Chemistry, Avcilar, Istanbul, TR-34320, Turkey \\ *Corresponding author at: Istanbul University, Engineering Faculty Department of Chemistry, Avcilar, Istanbul, TR-34320, Turkey. \\ Tel.: +90.212.4737070; Fax: +90.212.4737180.E-mail address: suhcan@gmail.com, spura@istanbul.edu.tr (S.P. Ergin).
}

ARTICLE INFORMATION
Received: 24 August 2012
Received in revised form: 27 September 2012
Accepted: 28 September 2012
Online: 31 December 2012
KEYWORDS
Ferric chloride
Ferrous chloride
Association constant
DMF-water mixtures
Electrolytic conductivity
Temperature dependence

\section{Introduction}

Dimethylformamide (DMF) is a versatile solvent for organic and inorganic substances. It is used as a solvent in peptide coupling for pharmaceuticals, in the production of acrylic fibers and plastics, in the development and production of pesticides, and in the manufacture of adhesives, synthetic leathers, fibers, films, and surface coatings [1]. Also, it is widely used as a solvent for electrochemical reactions, especially reductions [2].

DMF or DMF/water mixtures as solvent can be used due to: i) hydrolytic reactions of highly charged metal ions; ii) insolubility of the ligand or of one or more of the complexes to be formed. DMF readily dissolves many water-soluble salts as well as other sparingly soluble substances [3]. DMF as an aprotic solvent is an example of a "pure" dipolar fluid. Since the hydrogen bond is absent, the liquid structure of the neat DMF is determined by the dipole-dipole interactions between molecules. Addition of water modifies this picture; hydrogen bonds between oxygen atoms of the amide group and water molecules are created [4].

Conductometric studies in DMF-water have been performed on symmetrical electrolytes for many years [5-8]. The conductance behavior of unsymmetrical electrolytes, particularly in non-aqueous solvents and mixed solvents, has received relatively little attention [9-12]. This is due in large part to the difficulty encountered in analyzing such data since the usual methods require an arbitrary choice for some of the parameters required for the analysis [13].

Ferrous chloride $\left(\mathrm{FeCl}_{2}\right)$ and ferric chloride $\left(\mathrm{FeCl}_{3}\right)$ as asymmetrical electrolytes are readily soluble in DMF-water mixtures. While $\mathrm{FeCl}_{3}$ is used as a catalyst in organic synthesis, $\mathrm{FeCl}_{2}$ is employed as reducing agent [14]. In previous studies, the association of ferric ion with chloride ion in aqueous solutions was determined by spectrophotometric [15] and potentiometric methods [16]. In spectroscopic study, it was observed that the association constant value for ferric chloride was $30 \mathrm{dm}^{3} / \mathrm{mol}$ at $298.15 \mathrm{~K}$ and the association of ferric ion with chloride ion is endothermal. In my previous study [9], association of ferric chloride in primary alcohols was investigated by conductometrically. The association constants of $\mathrm{FeCl}_{3}$ were calculated by using conductivity data in terms of the Robinson-Stokes equations [17]. The association constant values for $\mathrm{FeCl}_{3}$ were calculated to be $467.82 \mathrm{dm}^{3} / \mathrm{mol}$ in methanol, $919.79 \mathrm{dm}^{3} / \mathrm{mol}$ in ethanol, $1253.23 \mathrm{dm}^{3} / \mathrm{mol}$ in 1 propanol, $1449.85 \mathrm{dm}^{3} / \mathrm{mol}$ in 1-butanol at $298.15 \mathrm{~K}$. However, the association and the conductance behavior of $\mathrm{FeCl}_{2}$ in mixed solvents have rarely been studied.

Most of the conductometric studies in DMF-water mixtures indicated that the electric conductivities of electrolytes in these mixtures were not studied too, in particular, as a function of temperature $[7,18,19]$. It seemed interesting to study by conductometrically the association equilibrium of $\mathrm{FeCl}_{2}$ and $\mathrm{FeCl}_{3}$ in various DMF-water mixtures as a function of temperature. Therefore, in present study, the association constants for $\mathrm{FeCl}_{2}$ and $\mathrm{FeCl}_{3}$ in various DMF-water mixtures at different temperatures were determined by analyzing conductivity data in terms of Kraus-Bray and Shedlovsky models. Thermodynamic parameters calculated from temperature dependence of these constants were investigated according to composition of DMF in mixed solvent and temperature.

\section{Experimental}

\subsection{Materials and methods}

Anhydrous $\mathrm{FeCl}_{2}$ and $\mathrm{FeCl}_{3}$ and DMF were purchased from Merck (Darmstad, Germany) products. 
Table 1. Density $\left(\rho^{*}\right)$, viscosity $\left(\eta^{*}\right)$ and relative permittivity $\left(\varepsilon^{*}\right)$ values for DMF-water mixtures at various temperatures and DMF compositions\#.

\begin{tabular}{|c|c|c|c|c|c|c|c|c|c|c|c|c|}
\hline \multirow{2}{*}{$T(\mathrm{~K})$} & \multicolumn{4}{|c|}{$\rho^{*}\left(\mathrm{~g} / \mathrm{cm}^{3}\right)$} & \multicolumn{4}{|c|}{$\eta^{*}$ (mPa.s) } & \multicolumn{4}{|c|}{$\varepsilon^{*}$} \\
\hline & $20 \%$ & $40 \%$ & $60 \%$ & $80 \%$ & $20 \%$ & $40 \%$ & $60 \%$ & $80 \%$ & $20 \%$ & $40 \%$ & $60 \%$ & $80 \%$ \\
\hline 288.15 & 1.0037 & 0.9932 & 0.9782 & 0.9650 & 2.5078 & 1.8570 & 1.3952 & 1.1014 & 71.94b & $65.00^{a, b}$ & $56.00^{a, b}$ & $46.95^{\mathrm{a}, \mathrm{b}}$ \\
\hline 298.15 & 0.9959 & 0.9839 & 0.9687 & 0.9555 & 2.3467 & 1.7458 & 1.3544 & 1.0765 & $68.02^{\mathrm{a}, \mathrm{b}}$ & $61.35^{\mathrm{a}, \mathrm{b}}$ & $53.10^{\mathrm{a}, \mathrm{b}}$ & $44.05^{\mathrm{a}, \mathrm{b}}$ \\
\hline 308.15 & 0.9880 & 0.9747 & 0.9593 & 0.9450 & 2.2156 & 1.7002 & 1.3319 & 1.0534 & 64.93a.b & $58.10^{\mathrm{a}, \mathrm{b}}$ & $50.00^{a, b}$ & $42.02^{\mathrm{a}, \mathrm{b}}$ \\
\hline 318.15 & 0.9789 & 0.9654 & 0.9497 & 0.9361 & 1.4923 & 1.2156 & 1.0012 & 0.8546 & $62.29^{b}$ & $56.18^{b}$ & $46.51^{b}$ & $39.06^{b}$ \\
\hline 328.15 & 0.9715 & 0.9558 & 0.9399 & 0.9267 & 1.0244 & 0.8768 & 0.7709 & 0.6665 & $60.34^{\mathrm{b}}$ & $53.91^{\mathrm{b}}$ & 43.47b & $37.03^{\mathrm{b}}$ \\
\hline
\end{tabular}

$\# \rho^{*}$ and $\eta^{*}$ : experimental values, $\varepsilon^{*}$ : data obtained from literature.

a Ref. [24].

b Ref. [25].

Table 2. Limiting equivalent conductivity $\left(\Lambda_{\mathrm{FeCl}_{n}}^{0}\right.$ ) values calculated according to Kraus-Bray and Shedlovsky models for $\mathrm{FeCl}_{2}$ and $\mathrm{FeCl}_{3}$ in $\mathrm{DMF}_{\mathrm{M}}$-water mixtures at various temperatures (T) and DMF compositions.

\begin{tabular}{|c|c|c|c|c|c|c|c|c|}
\hline \multirow{3}{*}{$T(\mathrm{~K})$} & \multicolumn{8}{|c|}{$\Lambda_{\mathrm{FeCl}_{2}}^{0}\left(\mathbf{S ~ c m}^{2} \mathbf{~ e q}^{-1}\right)$} \\
\hline & \multicolumn{4}{|c|}{ Kraus- Bray Model } & \multicolumn{4}{|c|}{ Shedlovsky Model } \\
\hline & $20 \%$ & $40 \%$ & $60 \%$ & $80 \%$ & $20 \%$ & $40 \%$ & $60 \%$ & $80 \%$ \\
\hline 288.15 & 21.22 & 14.33 & 22.45 & 39.67 & 21.41 & 14.52 & 22.19 & 39.78 \\
\hline 298.15 & 29.30 & 22.78 & 30.37 & 47.57 & 29.51 & 22.87 & 30.55 & 47.81 \\
\hline 308.15 & 39.63 & 33.05 & 40.72 & 57.92 & 39.90 & 33.21 & 40.90 & 58.25 \\
\hline 318.15 & 51.69 & 45.20 & 52.75 & 70.78 & 51.82 & 45.58 & 52.98 & 70.93 \\
\hline 328.15 & 66.35 & 59.16 & 67.52 & 85.80 & 66.68 & 59.41 & 67.69 & 86.02 \\
\hline \multirow{3}{*}{$T(\mathrm{~K})$} & \multicolumn{8}{|c|}{$\Lambda_{\mathrm{FeCl}_{3}}^{0}\left(\mathbf{S ~ c m}^{2} \mathbf{~ e q}^{-1}\right)$} \\
\hline & \multicolumn{4}{|c|}{ Kraus- Bray Model } & \multicolumn{4}{|c|}{ Shedlovsky Model } \\
\hline & $20 \%$ & $40 \%$ & $60 \%$ & $80 \%$ & $20 \%$ & $40 \%$ & $60 \%$ & $\mathbf{8 0 \%}$ \\
\hline 288.15 & 33.70 & 26.91 & 35.21 & 54.78 & 34.05 & 27.12 & 35.53 & 54.92 \\
\hline 298.15 & 42.94 & 36.56 & 44.20 & 61.54 & 43.20 & 36.77 & 44.37 & 61.75 \\
\hline 308.15 & 53.22 & 45.81 & 54.37 & 71.79 & 53.55 & 45.98 & 54.62 & 71.83 \\
\hline 318.15 & 65.91 & 57.83 & 67.02 & 84.73 & 66.12 & 58.00 & 67.23 & 84.93 \\
\hline 328.15 & 80.22 & 72.80 & 81.55 & 100.52 & 80.53 & 72.93 & 81.71 & 100.89 \\
\hline
\end{tabular}

$\mathrm{FeCl}_{2}$ and $\mathrm{FeCl}_{3}$ were purified by sublimation under an atmosphere of hydrogen chloride gas while DMF was purified as described in the literatures [20,21]. Double-distilled water with specific conductance of $2 \times 10^{-6} \mathrm{~S} / \mathrm{cm}$ at $298.15 \mathrm{~K}$ was used, after dissolved carbon dioxide was removed as described below.

Solutions of $\mathrm{FeCl}_{2}$ and $\mathrm{FeCl}_{3}$ in 20-80 wt \% DMF-water were prepared by weight. By using their measure densities, as described previously [11], the molalities were converted to molarities. The conductivity measurements of all solutions were performed in the range of $(1.691-10.558) \times 10^{-4} \mathrm{~mol} / \mathrm{dm}^{3}$, usually for ten concentration.

The specific conductivity value of DMF used in present study at $298.15 \mathrm{~K}$ was less than $10^{-7} \mathrm{~S} / \mathrm{cm}$, which correspond to the values cited in the literatures [5,18]. To analyze conductivity data, density and viscosity values for $20-80 \mathrm{wt} \%$ DMF-water mixtures have been determined experimentally at the same temperatures.

Density measurements were performed by using a $50 \mathrm{~cm}^{3}$ capacity Wertheim pycnometer with an uncertainty \pm 0.0002 $\mathrm{g} / \mathrm{cm}^{3}$. An Ostwald type viscometer was used for viscosity measurements. The flow times for the viscometer, measured with a precision stopwatch, ranged between 400 and $800 \mathrm{~s}$. The reported experimental viscosities are the average of four measurements, and their accuracy is $\pm 0.0002 \mathrm{mPa}$.s. Doubledistilled water was employed to calibrate the viscometer. The temperature was controlled with a thermostatted water bath (Veb MLW type 3230 ) to a precision of $\pm 0.01 \mathrm{~K}$. The experimental densities and viscosities of $20-80 \mathrm{wt} \%$ DMFwater mixtures are shown in Table 1 . The temperature variations during the density and viscosity measurements were $\pm 0.01 \mathrm{~K}$.

Electrical conductivities for $\mathrm{FeCl}_{2}$ and $\mathrm{FeCl}_{3}$ solutions in mixed solvents were measured from 288.15 to $328.15 \mathrm{~K}$ at $10 \mathrm{~K}$ intervals, by using a digital conductivity meter (CMD 750 WPA Model). The conductivity cell was a three-necked flask with a water jacket that was equipped with a nitrogen inlet and two platinized platinum electrodes. The conductivity cell was calibrated with $\mathrm{KCl}$ solutions over an appropriate concentration range. The cell constant was calculated using by
Barthel et al.'s [22] molar conductivity data for $\mathrm{KCl}$ (aq), and its value $0.482 \mathrm{~cm}^{-1}$ at $298.15 \mathrm{~K}$.

Before the beginning of the measurements, dissolved carbon dioxide was removed by bubbling moistened nitrogen gas through the solution in the cell for about $0.5 \mathrm{~h}$. In any given solution the measurements were carried out by starting at $288.15 \mathrm{~K}$ and elevating the temperature in steps of $10 \mathrm{~K}$. Throughout the measurements an atmosphere of nitrogen was maintained over the solution.

The reproducibility of the conductivity measurements was determined by repeating each experimental run three times, and was within $0.03 \%$. The accuracy temperature control was $\pm 0.01 \mathrm{~K}$.

\section{Results and discussion}

\subsection{Limiting equivalent conductivity and association constants}

The equivalent conductance, $\Lambda_{\mathrm{FeCl}_{n}}\left(\mathrm{n}=2\right.$ for $\mathrm{FeCl}_{2}$ and $\mathrm{n}=3$ for $\mathrm{FeCl}_{3}$ ), values of ferrous and ferric salts at various temperatures, were determined from specific conductance values of solutions. The resulted conductance values were analyzed initially by Kraus-Bray model of conductivity [23]. The model may be represented by Equation 1 .

$$
\frac{1}{\Lambda_{F e C l_{n}}}=\frac{1}{\Lambda_{F e C l_{n}}^{o}}+\frac{\Lambda_{F e C l_{n}} \cdot c}{\left(\Lambda_{F e C l_{n}}^{o}\right)^{2} \cdot K_{c}}
$$

where $K_{\mathrm{c}}$ is the dissociation constant and $\mathrm{c}$ is the concentration of solution. From the intercept and slope of the linear plot $1 / \Lambda_{\mathrm{FeCl}_{n}}$ versus $\Lambda_{\mathrm{FeCl}_{n}} . \mathrm{c}$, the limiting equivalent conductance $\left(\Lambda_{\mathrm{FeCl}_{n}}^{o}\right)$ and the dissociation constant $\left(K_{\mathrm{c}}\right)$ were obtained. The linearity of the plot is an indication for the presence of ion pairs of the electrolytes in equilibrium with the ions. The resulted values of $\Lambda_{\mathrm{FeCl}_{n}}^{o}$ are shown in Table 2 . 
Table 3. Association constant $\left(K_{\mathrm{A}}\right)$ values for $\mathrm{FeCl}_{2}$ and $\mathrm{FeCl}_{3}$ in DMF-water mixtures at various temperatures $(T)$ and DMF compositions.

\begin{tabular}{|c|c|c|c|c|c|c|c|c|}
\hline \multirow{2}{*}{$T(\mathrm{~K})$} & \multicolumn{4}{|c|}{$\left.\boldsymbol{K}_{\mathrm{A}(\mathrm{FeCl}}\right)$} & \multicolumn{4}{|c|}{$\left.\boldsymbol{K}_{\mathrm{A}(\mathrm{FeCl}}\right)$} \\
\hline & $20 \%$ & $40 \%$ & $60 \%$ & $80 \%$ & $20 \%$ & $40 \%$ & $60 \%$ & $80 \%$ \\
\hline 288.15 & 41.08 & 44.26 & 50.21 & 60.00 & 53.34 & 59.16 & 67.36 & 78.50 \\
\hline 298.15 & 49.69 & 53.36 & 60.47 & 70.40 & 63.55 & 69.42 & 77.68 & 87.90 \\
\hline 308.15 & 61.98 & 66.78 & 73.59 & 82.86 & 75.88 & 81.80 & 90.13 & 101.40 \\
\hline 318.15 & 79.35 & 82.85 & 85.66 & 99.44 & 90.35 & 96.33 & 104.74 & 116.16 \\
\hline 328.15 & 94.60 & 97.88 & 104.11 & 116.63 & 106.98 & 113.02 & 121.52 & 133.07 \\
\hline
\end{tabular}

Kraus-Bray model has certain inherent limitations especially the unaccountability for the effect of ionic mobility and activity coefficient on conductivity.

The Shedlovsky [24] model not only solves the above limitations but also provides absolute limiting equivalent conductance $\left(\Lambda_{\mathrm{FeCl}_{n}}^{o}\right.$ ) and association constant $\left(K_{\mathrm{A}}\right)$.

The model may be represented by Equation 2 .

$$
\begin{aligned}
& \frac{1}{S . \Lambda_{F e C l_{n}}}=\frac{1}{\Lambda_{F e C l_{n}}^{0}}+\frac{c \cdot \Lambda_{F e C l_{n}} \cdot S \cdot f_{ \pm}^{2} \cdot K_{A}}{\left(\Lambda_{F e C l_{n}}^{0}\right)^{2}} \\
& S=\left[\frac{\beta \sqrt{c \cdot \Lambda_{F e C l_{n}}}}{2 \cdot \Lambda_{F e C l_{n}}^{0 / 2}}+\sqrt{1+\frac{\beta^{2} \cdot c \cdot \Lambda_{F e C l_{n}}}{4 \cdot\left(\Lambda_{F e C l_{n}}\right)^{3}}}\right]^{2} \\
& \beta=\frac{8.20 x 10^{5} \Lambda_{F e C l_{n}}^{0}}{(\varepsilon T)^{3 / 2}}+\frac{82.5}{\eta(\varepsilon T)^{1 / 2}}
\end{aligned}
$$

$e$ is the electronic charge, $\varepsilon$ is relative permittivity of the mixed solvent, $k$ is Boltzmann constant, $T$ is absolute temperature, and $\eta$ is the viscosity of the mixed solvent. Relative permittivity $(\varepsilon)$ values for 20-80 wt \% DMF-water mixtures at varying temperatures from 288.15 to $328.15 \mathrm{~K}$ were obtained from literatures $[25,26]$, and they were given together with their experimental (in this work) density and viscosity values in Table 1.

According to Shedlovsky Model, $\Lambda_{F e C l}^{o}$ and $K_{\mathrm{A}}$ for $\mathrm{FeCl}_{2}$ and $\mathrm{FeCl}_{3}$ were obtained from the intercept and slope of the linear plot of $1 / S \Lambda_{\mathrm{FeCl}_{n}}-c \Lambda_{\mathrm{FeCl}_{n}} S f_{ \pm}^{2}$. $\mathrm{For} \mathrm{FeCl}_{2}$ and $\mathrm{FeCl}_{3}$ in DMF-water mixed solvents, $\Lambda_{\mathrm{FeCl}}^{o}$ values calculated by Shedlovsky model are given with those calculated by KrausBray model in Table 2.

As shown in Table 1, $\Lambda_{\mathrm{FeCl}_{3}}^{o}$ values calculated by both Shedlovsky model and Kraus-Bray Model were higher than $\Lambda_{\mathrm{FeCl}_{2}}^{o}$ values. $\Lambda_{\mathrm{FeCl}_{n}}^{o}$ values for both $\mathrm{FeCl}_{2}$ and $\mathrm{FeCl}_{3}$ in 20-80 wt \% DMF-water mixtures at all temperatures increased with increase in temperature due to increase in thermal energy, and in turn, the mobility of the ions.

Effect of relative permittivity of solvent on the limiting equivalent conductivity of electrolytes in mixed solvent is important, but at the same time, ion-solvent interactions undoubtedly can also play an important role. In some instances, ion-solvent interactions may be more important than the relative permittivity of mixed solvent.

The increase in relative permittivity of the solvent mixture (Table 1) leads to the decrease in conductivity. This situation is valid for the DMF content from 20 to $40 \%$ wt in mixed solvents in Table 2, but it is not the case for 40 to $80 \%$ DMF-water mixtures. Increasing in temperature decreases the relative permittivity of solvent/solvent mixture, but it increases the mobility of ion. For that reason, it is expected that the limiting equivalent conductivity should increase when the increase in ion- solvent interactions with temperature is higher than the decrease in relative permittivity. This finding is consistent with those in mixed solvents reported in many literatures $[7,11,19,27]$.

The mixing of non-aqueous solvent with water brings variation in solvent-solvent interactions leading to variation in permittivity and production of bulky solvent mixture molecules.

The increasing in the composition of DMF in DMF-water mixtures increases the limiting equivalent conductance, probably due to the breakdown of the three-dimensional structure of water. The hydrogen bond formed between DMF and water is stronger than in pure water due to dipole-dipole interaction, which leads to the association of DMF and water molecules, leading to the reduction in ionic mobility [28].

Association constant $\left(K_{\mathrm{A}}\right)$ values for $\mathrm{FeCl}_{2}$ and $\mathrm{FeCl}_{3}$ were determined from the slope of Shedlovsky plot in DMF-water mixtures at different temperatures and they are given in Table 3. Also, the temperature dependences of $K_{\mathrm{A}}$ are plotted as $\ln K_{\mathrm{A}}$ versus $1 / T$ curves. $\operatorname{Ln} K_{\mathrm{A}}-1 / T$ plots are shown in Figure 1 and 2 for $\mathrm{FeCl}_{2}$ and $\mathrm{FeCl}_{3}$, respectively.

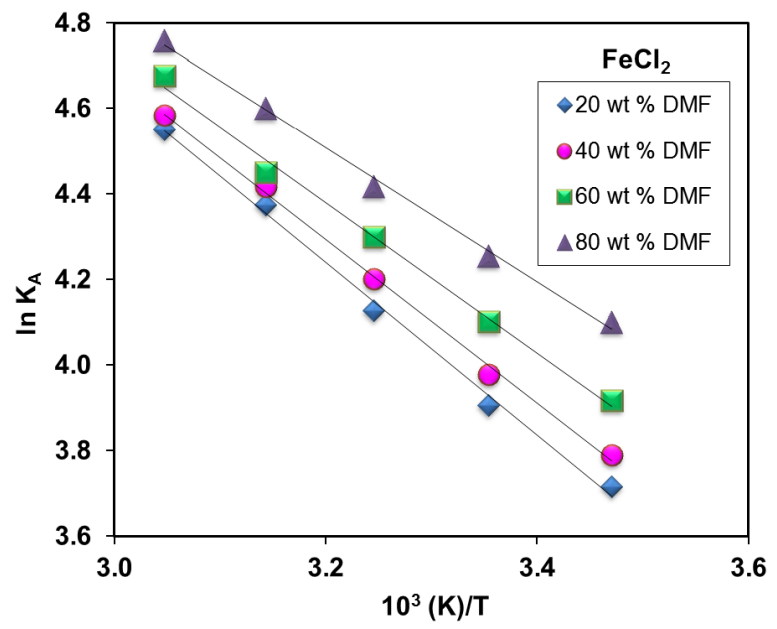

Figure 1. $\mathrm{Ln} K_{\mathrm{A}}$ as a function of the reciprocal temperature for $\mathrm{FeCl}_{2}$ in various DMF-water mixtures. 


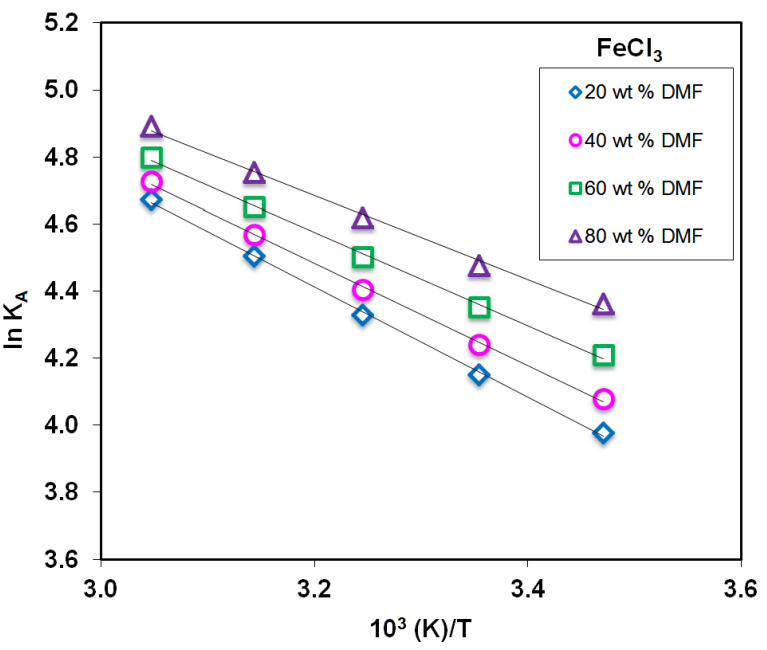

Figure 2. $\mathrm{Ln} K_{\mathrm{A}}$ as a function of the reciprocal temperature for $\mathrm{FeCl}_{3}$ in various DMF-water mixtures.

As shown in Table 3, Figure 1 and 2, the $K_{\mathrm{A}}$ values for $\mathrm{FeCl}_{2}$ were less than those for $\mathrm{FeCl}_{3}$ in all DMF-water mixtures and they increased with increase in temperature proposing endothermic character of the system. Increase in the $K_{\mathrm{A}}$ with the increases in temperature may be attributed to an indication of the ion association [25].

As seen from Table 3, Figure 1 and 2, $K_{\mathrm{A}}$ values for both $\mathrm{FeCl}_{2}$ and $\mathrm{FeCl}_{3}$ indicated an decreased in the order $80 \mathrm{wt} \%$ DMF > 60 wt \% DMF > 40 wt \% DMF > 20 wt \% DMF in mixed solvents at all the temperatures. This may be attributed to the association constant increasing with a decrease in the relative permittivity of DMF-water mixture. These results are in agreement with many literatures dealing with this subject [10,29-31].

The association constants for $\mathrm{FeCl}_{2}$ and $\mathrm{FeCl}_{3}$ in DMF-water mixed solvents are plotted in Figure 3 as a function of the reciprocal relative permittivity. As seen from these plots, the magnitude of $K_{\mathrm{A}}$ is related to diminish in relative permittivity of DMF-water mixture.

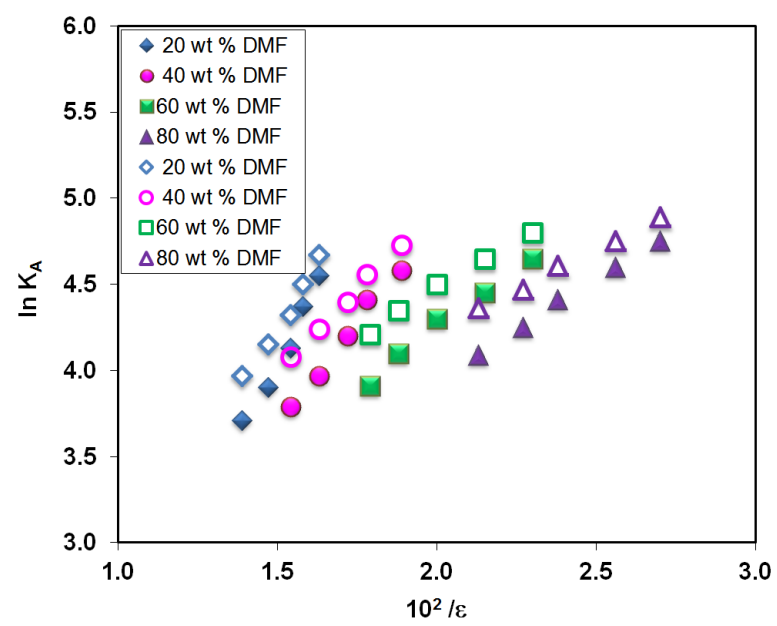

Figure 3. Ln $K_{\mathrm{A}}$ as a function of the reciprocal relative permittivity $(\varepsilon)$ for $\mathrm{FeCl}_{2}$ (closed symbols) and $\mathrm{FeCl}_{3}$ (open symbols) in various DMF-water mixed solvents at different temperatures.

The variation in $K_{\mathrm{A}}$ to another from one composition in 20$80 \mathrm{wt} \%$ DMF-water mixtures is primarily due to the change in relative permittivity and also due to the formation of intermolecular hydrogen bonding, causing not only an increase in the thickness of the ionic atmosphere surrounding the polar species but also a reduction in the repulsion between them. The decrease in the hydration of the ions, due to the presence of solvent mixture molecules, leads to an increase in the association constant values $[10,11,28]$.

\subsection{Thermodynamic parameters}

It was used the conventional thermodynamic equations in order to obtain standard Gibbs' free energy, enthalpy and entropy changes of association constant.

The standard enthalpy changes, $\Delta H^{\circ}$, were calculated from the following equation

$\ln K_{A}=\left(-\Delta H^{\circ} / R T\right)+\mathrm{I}$

For this purpose, as shown in Figure 2, it has been plotted with the values of $\ln K_{\mathrm{A}}$ against to reciprocal temperatures in 20-80 wt \% DMF-water mixtures. For $\mathrm{FeCl}_{2}$ and $\mathrm{FeCl}_{3}$ in DMFwater solvents, $\Delta H^{\circ}$ values were obtained by using from slopes of these curves and were shown in Table 4.

The standard Gibbs' free energy changes, $\Delta G^{\circ}$, and standard entropy changes, $\Delta S^{\circ}$, were calculated from Equation 9 and 10.

$\Delta G^{0}=-R T \ln K_{A}$

$\Delta S^{\circ}=\left(\Delta H^{\circ}-\Delta G^{\circ}\right) / T$

$\Delta G^{\circ}$ and $\Delta S^{\circ}$ parameters were also given in Table 4. As shown in Table 4, $\Delta G^{\circ}$ values for both $\mathrm{FeCl}_{2}$ and $\mathrm{FeCl}_{3}$ in all DMF-water mixtures were decreased as the temperature increased. Large negative values of $\Delta G^{\circ}$ indicate that the association process is spontaneous. The decrease of $\Delta G^{\circ}$ values to more negative with increasing temperature makes easier the transfer of the released solvent molecules into bulk solvent and leads to more negative $\Delta G^{\circ}$ values. The $\Delta G^{\circ}$ values for $\mathrm{FeCl}_{2}$ were higher than those for $\mathrm{FeCl}_{3}$. As the composition of DMF in mixed solvents was increase, the $\Delta G^{\circ}$ values indicated a decrease at all temperatures.

As seen from Table 4 , the $\Delta H^{\circ}$ values for $\mathrm{FeCl}_{2}$ were higher than those for $\mathrm{FeCl}_{3}$ in all DMF-water mixtures and at all temperatures. The $\Delta H^{\circ}$ values for both $\mathrm{FeCl}_{2}$ and $\mathrm{FeCl}_{3}$ were found to be positive in all mixed solvents. Obtained positive and high $\Delta H^{\circ}$ values can be attributed to the presence of endothermic interactions between of the ions for $\mathrm{FeCl}_{2}$ and $\mathrm{FeCl}_{3}$. The negative $\Delta H^{\circ}$ values could not be predicted from the ion association theories [32,33]. $\Delta H^{\circ}$ values for both $\mathrm{FeCl}_{2}$ and $\mathrm{FeCl}_{3}$ in all DMF-water mixtures increased with an increase in the temperature. This was attributed to the endothermic behavior of the system. Also, they indicated a decrease as the composition of DMF increased. This was attributed to a change in hydrogen- bond strength in mixed solvents.

As presented in Table $4, \Delta S^{\text {o }}$ values of $\mathrm{FeCl}_{2}$ were smaller than those for $\mathrm{FeCl}_{3}$ in all DMF-water mixed solvents. From Table 4 , it was observed that, while the values of $\Delta S^{\circ}$ for $\mathrm{FeCl}_{3}$ decreased with a increase in the temperature, for $\mathrm{FeCl}_{2}$, they indicated some disorder. The main factors which govern the standard entropy of ion association of electrolytes are (i) the size and shape of the ions, (ii) charge density on ions, (iii) electrostriction of the solvent molecules around the ions, and (iv) the penetration of the solvent molecules inside the space of the ions [34]. For both $\mathrm{FeCl}_{2}$ and $\mathrm{FeCl}_{3}, \Delta S^{\text {o }}$ values indicated a decrease, as the composition of DMF in DMF-water mixed solvents increased. This can be attributed to two phenomena; a change in hydrogen- bond strength or a decrease in the average number of hydrogen bond [35]. The values of $\Delta S^{\circ}$ for both $\mathrm{FeCl}_{2}$ and $\mathrm{FeCl}_{3}$ were found to be positive and close to each other. The positive $\Delta S^{\circ}$ values may be ascribed that the association process is entropically favorable. 
Table 4. Thermodynamic parameters calculated for $\mathrm{FeCl}_{2}$ and $\mathrm{FeCl}_{3}$ in 20-80 wt \% DMF-water mixtures in various temperatures.

\begin{tabular}{|c|c|c|c|c|c|c|c|}
\hline \multirow{3}{*}{ DMF (wt \%) } & \multirow{3}{*}{$T(K)$} & \multicolumn{3}{|c|}{$\mathrm{FeCl}_{2}$} & \multicolumn{3}{|c|}{$\mathrm{FeCl}_{3}$} \\
\hline & & $\Delta H^{o}$ & $\Delta G^{o}$ & $\Delta S^{o}$ & $\Delta H^{o}$ & $\Delta G^{o}$ & $\Delta S^{o}$ \\
\hline & & $\left(\mathrm{kJ} \mathrm{K}^{-1} \mathrm{eq}^{-1}\right)$ & $\left(\mathrm{kJ} \mathrm{K}^{-1} \mathrm{eq}^{-1}\right)$ & $\left(\mathrm{J} \mathrm{K}^{-1} \mathrm{eq}^{-1}\right)$ & $\left(\mathrm{kJ} \mathrm{K}^{-1} \mathrm{eq}^{-1}\right)$ & $\left(\mathrm{kJ} \mathrm{K}^{-1} \mathrm{eq}^{-1}\right)$ & $\left(\mathrm{J} \mathrm{K}^{-1} \mathbf{e q}^{-1}\right)$ \\
\hline \multirow{5}{*}{20} & 288.15 & & -8.90 & 89.12 & \multirow{5}{*}{13.70} & -9.53 & 91.29 \\
\hline & 298.15 & & -9.68 & 88.75 & & -10.29 & 90.79 \\
\hline & 308.15 & 16.78 & -10.57 & 88.76 & & -11.09 & 90.44 \\
\hline & 318.15 & & -11.57 & 89.10 & & -11.91 & 90.18 \\
\hline & 328.15 & & -12.41 & 88.96 & & -12.74 & 89.98 \\
\hline \multirow{5}{*}{40} & 288.15 & \multirow{5}{*}{15.93} & -9.08 & 86.81 & \multirow{5}{*}{12.74} & -9.77 & 89.22 \\
\hline & 298.15 & & -9.85 & 86.51 & & -10.51 & 88.70 \\
\hline & 308.15 & & -10.76 & 86.64 & & -11.28 & 88.33 \\
\hline & 318.15 & & -11.68 & 86.81 & & -12.08 & 88.06 \\
\hline & 328.15 & & -12.50 & 86.67 & & -12.90 & 87.86 \\
\hline \multirow{5}{*}{60} & 288.15 & \multirow{5}{*}{14.65} & -9.38 & 83.41 & \multirow{5}{*}{11.61} & -10.09 & 85.86 \\
\hline & 298.15 & & -10.16 & 83.26 & & -10.78 & 85.33 \\
\hline & 308.15 & & -11.01 & 83.30 & & -11.53 & 84.98 \\
\hline & 318.15 & & -11.77 & 83.06 & & -12.08 & 84.73 \\
\hline & 328.15 & & -12.67 & 83.28 & & -12.90 & 84.56 \\
\hline \multirow{5}{*}{80} & 288.15 & \multirow{5}{*}{13.06} & -9.81 & 79.39 & \multirow{5}{*}{10.47} & -10.45 & 81.61 \\
\hline & 298.15 & & -10.54 & 79.18 & & -11.10 & 81.03 \\
\hline & 308.15 & & -11.31 & 79.12 & & -11.83 & 80.80 \\
\hline & 318.15 & & -12.16 & 79.30 & & -12.57 & 80.59 \\
\hline & 328.15 & & -12.98 & 79.37 & & -13.34 & 80.47 \\
\hline
\end{tabular}

\section{Conclusion}

Conductivity measurements for $\mathrm{FeCl}_{2}$ and $\mathrm{FeCl}_{3}$ in 20-80 wt $\%$ DMF-water mixtures indicated that their equivalent conductivities increased with increasing DMF composition as well as increasing temperature. When conductance data was analyzed by Kraus-Bray and Shedlovsky Models, $\Lambda_{\mathrm{FeCl}_{3}}^{o}$ conductivity values calculated from both models for $\mathrm{FeCl}_{3}$ were found to be higher than those for $\mathrm{FeCl}_{2}$. Increasing with temperature of the $K_{\mathrm{A}}$ values determined from Shedlovsky model for $\mathrm{FeCl}_{2}$ and $\mathrm{FeCl}_{3}$ in mixed solvents was attributed to endothermic character of the system. As the composition of DMF in mixed solvent increased, the $K_{\mathrm{A}}$ values for both $\mathrm{FeCl}_{2}$ and $\mathrm{FeCl}_{3}$ indicated an increase. This was attributed to the association constant increasing with a decrease in the relative permittivity of the mixed solvent. $\Delta G^{\mathrm{o}}$ values for $\mathrm{FeCl}_{2}$ and $\mathrm{FeCl}_{3}$ decreased with the increase in temperature in 20-80 wt \% DMF-water mixtures. The more negative values of $\Delta G^{\circ}$ calculated for $\mathrm{FeCl}_{3}$ indicated that that association process is more spontaneous of those for $\mathrm{FeCl}_{2}$. For both $\mathrm{FeCl}_{2}$ and $\mathrm{FeCl}_{3}$, the decrease of $\Delta S^{\circ}$ with increasing in the composition of DMF in mixed solvents can be attributed to a change in hydrogenbond in mixed solvents. The positive $\Delta H^{\circ}$ and the negative $\Delta G^{\circ}$ values calculated for $\mathrm{FeCl}_{2}$ and $\mathrm{FeCl}_{3}$ may be attributed to the endothermic behavior of the system.

\section{References}

[1]. Chadwick, S. S. Enclopedia of Indusrial Chemistry; Wiley-VCH; Weinheim, 2006.

[2]. Juillard, J. Pure Appl. Chem. 1977, 49, 885-892.

[3]. Mollar, M.; Castro, I.; Lloret, F.; Julve, M.; Faus, J.; Latorre, J. Trans. Met. Chem. 1991, 16, 31-34.

[4]. Zielkiewich, J. J. Phys. Chem. 1995, 99, 4787-4793.

[5]. Singh, D.; Bahadur, L.; Ramanamurti, M. V. J. Sol. Chem. 1977, 6, 703715 .

[6]. Bahadur, L.; Ramanamurti, M. V. Can. J. Chem. 1984, 62, 1051-1056.

[7]. Sjezig, A.; Bald, A.; Gregorowicz, J. Monatsh. Chem. 1997, 128, $1093-$ 1100.

[8]. Sharma, R.; Sharma, B.; Pradhan, D.; Dahal, S. J. Chem. Eng. Data 2010, 55, 5382-5387.

[9]. Pura, S. J. Mol. Liq. 2007, 136, 64-70.

[10]. Pura, S.; Atun, G. J. Chem. Eng. Data. 2002, 47, 1103-1109.

[11]. Pura, S.; Atun, G. J. Sol. Chem. 2003, 32, 341-361.

[12]. Bhat, J. I.; Sreelatha, T. N. J. Mol. Liq. 2005, 116, 175-180.

[13]. Broadwater, T. L.; Murpy, T. J.; Evans, D. F. J. Phys. Chem. 1976, 80, 753-756.

[14]. Holleman, A. F.; Wiberg, E. Inorganic Chemistry, Academic Press, San Diego, 2001.
[15]. Rabinowitch, E.; Stockmayer, W. H. J. Am. Chem. Soc. 1942, 33, 335342.

[16]. Moller, M. J. Phys. Chem. 1937, 41, 1123-1128.

[17]. Robinson, R. A.; Stokes, R. H. Electrolyte Solutions, 2nd edn; Butterworths; London; 1959; Chapter 7.

[18]. Sjezig, A.; Bald, A.; Gregorowicz, J.; Kınart C. M. Phys. Chem. Liq. 1977, 31, 189-199.

[19]. Sjezig, A.; Bald, A. J. Mol. Liq. 1998, 75, 237-252.

[20]. Safonova, L. B.; Sakharov, D. V.; Shmukler, L. E.; Kolker, A. M. Phys. Chem. Chem. Phys. 2001, 3, 819-823.

[21]. Riddick, J. A.; Bunger, W. B.; Sakano, T. K. Organic Solvents, Physical Properties and Methods of Purification, $4^{\text {th }}$ edn, Wiley Interscience, New York, 1986

[22]. Barthel, J.; Feurlein, F.; Neuder, R.; Watcher, R. J. J. Sol. Chem. 1980, 9, 209-219.

[23]. Kraus, C. A.; Bray, W. C. A. J. Am. Chem. Soc. 1913, 35, 1315-1434.

[24]. Shedlovsky, T. J. Franklin Int. 1938, 25, 739-743.

[25]. Bhat, J. I.; Shivakumar, H. R. J. Mol. Liq. 2004, 111, 101-108.

[26]. Parsons, R. Handbook of Electrochemical Constants, Butterworths Scientific Publication, London, 1959.

[27]. Kubota, E.; Yokoi, M. Bull. Chem. Soc. Jpn. 1976, 49, 2674-2686.

[28]. Bhat, J. I.; Shetty, M. K. J. Chem. Eng. Data 2010, 55, 4721-4724.

[29]. Kubota, E.; Yokoi, M.; Bull. Chem. Soc. Jpn. 1977, 50, 1425-1430.

[30]. Islam, M. R.; Ahmad, I.; Ansari, A. A. J. Electrochem. Soc. 1989, 136, 1303-1308.

[31]. Das, B.; Hazra, K. D. J. Sol. Chem. 1998, 27, 1021-1031.

[32]. Fuoss, R. M. J. Am. Chem. Soc. 1958, 80, 5059-5061.

[33]. Yokoyama, H.; Yamatera, H. A. Bull. Chem. Soc. Jpn. 1975, 48, 17701776.

[34]. Victor, P. J.; Muhuri, P. K.; Das, B.; Hazra, D. K. J. Phys. Chem. B. 1999, 103, 11227-11232.

[35]. Zijie, L.; Evangelos, M.; Digby, D.; Macdonald, M. L. J. Phys. Chem. A. 2009, 113, 12207-12214. 